Article

\title{
Common Mental Disorders and Risk Factors in Urban Tanzania
}

\section{Rachel Jenkins ${ }^{1, *}$, Joseph Mbatia ${ }^{2}$, Nicola Singleton ${ }^{3}$ and Bethany White ${ }^{4}$}

1 WHO Collaborating Centre (Mental Health), Institute of Psychiatry, Kings College London, UK; E-Mail: Rachel.jenkins@kcl.ac.uk

2 Mental Health, Ministry of Health, Tanzania; E-Mail: jmbatia@muchs.ac.tz

3 Policy \& Research, UK Drug Policy Commission; UK;

E-Mail: NSingleton@ukdpc.org.uk

4 WHO Collaborating Centre (Mental Health), Institute of Psychiatry, Kings College London, UK; E-Mail: bwhite@nchecr.unsw.edu.au

* Author to whom correspondence should be addressed; E-Mail: r.jenkins@iop.kcl.ac.uk; Tel.: +44-(0)20-7848-0668; Fax: +44-(0)20-7848-0669.

Received: 24 April 2010; in revised form: 24 May 2010 / Accepted: 26 May 2010 / Published: 14 June 2010

\begin{abstract}
A cross sectional population based epidemiological survey of 899 adults aged between 15 and 59 was undertaken in two urban areas of demographic surveillance sites in Dar es Salaam, Tanzania, using the Clinical Interview Schedule Revised. Significantly higher rates were found among those who had experienced more than three severe life events in the last six months and relationship difficulties and death of a loved one.
\end{abstract}

Keywords: common mental disorder; Tanzania; poverty

\section{Introduction}

Although most developing countries are expected to achieve the Millennium Development Goal of a $50 \%$ reduction in the number of people living on less than $\$ 1$ per day by 2015, this is unlikely in many sub-Saharan African countries including Tanzania [1], which remains one of the poorest nations in the world, with a gross national income of $\$ 300$ per capita in 2003 [2]. The Government of Tanzania 
has established key national economic policy frameworks [3,4], and has recognised the links between poverty and physical ill health, but the role of mental health had not been explicitly considered [5], despite the fact that in 1990 the World Bank estimated that neuropsychiatric disorders formed 10.5\% of global burden of disease (DALYs) and suggested that this could rise to $15 \%$ in 2020 . In fact they have already reached 19\% [6]. They comprise 5 of the 10 leading causes of disability, and account for $28 \%$ of years of life lived with a disability. Depression alone is expected to rise from the fourth to the second leading cause of global disease burden as measured by DALYs by 2030. Depression contributes more than $10 \%$ of years of life lived with a disability, and suicide was the 10th leading cause of death. These figures do not take account of family burden or wider social costs.

The current study therefore aimed to examine the relationships in urban Tanzania between the rates of common mental disorder (CMD), such as depression and anxiety, and socio-economic factors, demographic characteristics and social functioning.

\section{Methods}

\subsection{Sites}

As previously described [7], in September and October 2003 a population-based survey was conducted in two urban areas of Dar es Salaam, Tanzania's largest city with a population of 2.5 million. The areas were sites of the Adult Morbidity and Mortality Project (AMMP) [8,9], selected to ensure subpopulations of differing socio-economic circumstances. Ilala- Shaurimoyo (Ilala municipality) was a relatively middle-income area and Mtoni- Saba Saba (Temeke municipality) was a lower-income area [10].

\subsection{Sample}

A systematic random sample of 1,100 adults aged 15-59 was drawn from a random starting point from the entirely enumerated population of two geographically defined areas; 550 from the eligible population of 4,690 in Ilala-Shaurimoyo, and 550 from an eligible population of 11,620 in Mtoni-Saba Saba [11]. If the person randomly selected for interview in each household had moved away, the person who had moved into the house was interviewed instead. It was individuals rather than households which were enumerated, formed by the AMMP into a database of names, and hence sampled. Therefore, the sample was designed to be large enough in each area to provide estimates with adequate and similar levels of precision.

\subsection{Procedure}

The survey was coordinated by the Mental Health Section of the Ministry of Health, the Health Research Systems Section of the Directorate of Planning, and Dar es Salaam City Health Services. Interviewers were trained volunteer community health workers based in primary healthcare centres. Informed consent was obtained from all respondents. 


\subsection{Instruments}

Information collected included demographic characteristics, socio-economic factors, recent life events and perceived social support. The Clinical Interview Schedule- Revised (CIS-R) [12], assessed common mental disorder, the Psychosis Screening Questionnaire (PSQ) [13], indicated the presence of psychotic symptoms, and the Alcohol Use Disorders Identification Test (AUDIT) [14], measured hazardous alcohol use. See related articles on psychotic symptoms [15], and alcohol use [7].

Demographic information collected included age, sex, ethnicity, marital status and household status (head, spouse or other). Socio-economic factors assessed included employment status, education attainment, income (whether or not the person had a cash income), housing tenure (owned or rented) and type of accommodation (whole house or room only).

The CIS-R [16], is a gold standard instrument for use by lay interviews in assessing psychopathology in community settings, which has been widely used in high [17-19], and low income countries [20-22], including Tanzania [23] . The CIS-R measures the presence of 14 symptom-types in the preceding month and if present, the frequency, duration and severity of each symptom in the past week. Scores taken together with algorithms based on the ICD-10 [24], provide diagnoses of depressive episode (mild, moderate or severe), obsessive compulsive disorder, panic disorder, phobic disorder, generalised anxiety disorder and mixed anxiety/depressive disorder. For the purpose of the current paper however, a score of 12 or more across the 14 sections of the survey was considered an indication of "any CMD”, as used in other CIS-R studies [12].

Respondents were given a list of 11 different stressful life events and asked to say which, if any, they had experienced in the last six months. The list included health risks (serious illness, injury or assault to self or close relative), loss of a loved one (death of a relative; death of a close friend), relationship difficulties (separation or divorce; serious problem with a close friend or relative); income instability (being made redundant or sacked; having looked for work for over a month; loss of the equivalent of three months income) and legal problems (problems with the police involving a court experience; something of value lost or stolen). The list was developed for the 1993 British psychiatric morbidity survey [17,25], further modified for the 1997 prisons survey [26], and slightly tailored for the Tanzania context. Scores were grouped into either "none”, “one”, "two" and "three or more” life events and were also analysed by category.

Perceived social support was assessed from respondents' answers to seven questions which were used in the 1992 Health Survey for England [27], and the ONS Surveys of Psychiatric Morbidity [18,28]. The seven questions take the form of statements that individuals could say were not true, partly true or certainly true for them in response to the question 'There are people I know who'; (i) Do things to make me happy; (ii) Who make me feel loved; (iii) Who can be relied on no matter what happens; (iv) Who would see that I am taken care of if I needed to be; (v) Who accept me just as I am; (vi) Who make me feel an important part of their lives; and (vii) Who give me support and encouragement. Results were categorised into no, moderate of sever lack of perceived social support.

Information on social networks was obtained through questions about the number of friends or relatives who informants felt close to, including (i) Adults who lived with the respondent and to whom they felt close; (ii) Relatives living elsewhere to whom they felt close; and (iii) Friends or acquaintances living elsewhere who informants would describe as close or good friends. These 
questions were taken from earlier psychiatric morbidity surveys [29,30], and results grouped "none to three”, "four to eight” and "nine or more”.

\subsection{Analysis}

Data were analysed using SPSS software for Windows Version 15 [31]. Chi squared $\left(\chi^{2}\right)$ tests examined demographic and socio-economic differences between the areas, as well as differences in perceived social support and recent life events.

Odd ratios (ORs) with 95\% confidence intervals (CIs) were calculated to determine significant associations with the presence of any CMD (i.e., a CIS-R score of 12 more) and then "any CMD” was examined as the dependent variable in multivariate logistic regression. All factors significant in bivariate analyses and those that differed between areas plus age and gender were entered forward stepwise into the model. The 11 types of life event were collapsed into five categories and entered separately into the model to determine which categories of event were most strongly associated with CMD.

\subsection{Ethics Approval}

Approval was granted by National Institute for Medical Research, Ministry of Health, United Republic of Tanzania and South London and Maudsley (SLaM), National Health Service (NHS) Foundation Trust.

\section{Results}

\subsection{Response Rate}

The overall response rate was $82 \%$ with 899 out of 1,100 households approached completing the survey. Participation was higher in Ilala-Shaurimoyo where 481 out of 550 (87\%) people agreed to complete the survey compared to Mtoni-Saba Saba households where 418 from 550 (76\%) participated.

\subsection{Differences between Areas}

Living in poorer Saba Saba was associated with higher rates of CMD (4.1\%) compared to the middle income area of Ilala Ilala (2.3\%) although the difference was not statistically significant. Table 1 presents demographic and other characteristics by area. Respondents from Saba Saba and Shaurimoyo were of comparable age $(p=0.51)$, gender $(p=0.76)$ and marital status $(p=0.69)$ but respondents from Ilala were significantly more likely to be household head ( $p<0.001$ ), identify as non-African $(p<0.001)$ and to report renting their home $(p=0.04)$. Living in poorer Saba Saba was associated with unemployment $(p<0.001)$ and with younger school leaving age $(p=0.01)$. Saba Saba respondents also reported a significantly higher number of adverse life events in the six months preceding interview $(\mathrm{P}<0.001)$. 
Table 1. Demographic \& socio-economic factors, social support and life events by area.

\begin{tabular}{|c|c|c|c|c|}
\hline & $\begin{array}{c}\text { Saba Saba } \\
n=418(\%)\end{array}$ & $\begin{array}{c}\text { Ilala } \\
\mathrm{n}=\mathbf{4 8 1}(\%)\end{array}$ & $\begin{array}{c}\text { Unadjusted } \\
\text { odds ratio } \\
(95 \% \mathrm{CI})\end{array}$ & P value $\left(\chi^{2}\right)$ \\
\hline \multicolumn{5}{|l|}{ Gender } \\
\hline Male & 44 & 43 & 1.00 & \\
\hline Female & 56 & 57 & $1.04(0.80-1.36)$ & 0.760 \\
\hline \multicolumn{5}{|l|}{ Age } \\
\hline $16-24$ & 32 & 29 & 1.00 & \\
\hline $25-34$ & 34 & 34 & $1.11(0.80-1.54)$ & \\
\hline $35+$ & 34 & 37 & $1.21(0.88-1.68)$ & 0.508 \\
\hline \multicolumn{5}{|l|}{ Marital status } \\
\hline Married/cohabitating & 55 & 56 & 1.00 & \\
\hline Single & 38 & 36 & $0.93(0.71-1.23)$ & \\
\hline Widowed/divorced/separated & 8 & 9 & $1.16(0.71-1.89)$ & 0.687 \\
\hline \multicolumn{5}{|l|}{ Relationship to household head } \\
\hline Head & 35 & 45 & 1.00 & \\
\hline Spouse/partner & 32 & 33 & $0.81(0.59-1.11)$ & \\
\hline Other & 34 & 23 & $0.52(0.38-0.73)$ & $<0.001$ \\
\hline \multicolumn{5}{|l|}{ Ethnic group } \\
\hline Black African & 98 & 88 & 1.00 & \\
\hline Other & 2 & 12 & $7.6(3.47-17.09)$ & $<0.001$ \\
\hline \multicolumn{5}{|l|}{ Employment status } \\
\hline Working & 32 & 39 & 1.00 & \\
\hline Unemployed & 9 & 3 & $0.26(0.13-0.51)$ & \\
\hline Economically inactive & 59 & 58 & $0.81(0.60-1.08)$ & $<0.001$ \\
\hline \multicolumn{5}{|l|}{ Own/rent accommodation } \\
\hline Owns & 49 & 41 & 1.00 & \\
\hline Rents & 48 & 55 & $1.35(1.03-1.77)$ & \\
\hline Rent free & 2 & 4 & $1.99(0.90-4.38)$ & 0.036 \\
\hline \multicolumn{5}{|l|}{ Type of accommodation } \\
\hline Whole house & 46 & 41 & 1.00 & \\
\hline Rooms/flat/other & 54 & 59 & $1.24(0.95-1.62)$ & 0.107 \\
\hline \multicolumn{5}{|l|}{ Age left full time education } \\
\hline 13 or under/Never went & 8 & 5 & 1.00 & \\
\hline $14-16$ & 38 & 38 & $1.69(0.94-3.07)$ & \\
\hline 17 or 18 & 24 & 24 & $1.69(0.91-3.12)$ & \\
\hline $19+\mathrm{yrs}$ & 20 & 27 & $2.32(1.25-4.30)$ & \\
\hline Still at school & 10 & 6 & $1.02(0.49-2.11)$ & 0.012 \\
\hline \multicolumn{5}{|l|}{ Income } \\
\hline Yes & 44 & 41 & 1.00 & \\
\hline No & 55 & 59 & $1.14(0.87-1.50)$ & 0.349 \\
\hline
\end{tabular}


Table 1. Cont.

\begin{tabular}{lcccc}
\hline Perceived social support & & & & \\
Severe lack & 21 & 21 & 1.00 & \\
Moderate lack & 37 & 34 & $0.94(0.65-1.38)$ & \\
No lack & 41 & 44 & $1.08(0.75-1.56)$ & 0.708 \\
Size of Primary Social support group & & & & \\
$0-3$ & 14 & 15 & 1.00 & \\
$4-8$ & 42 & 49 & $1.12(0.75-1.67)$ & \\
9 or more & 44 & 36 & $0.79(0.53-1.18)$ & 0.408 \\
Number of life events & & & & \\
None & 56 & 72 & 1.00 & \\
1 & 26 & 21 & $0.61(0.44-0.84)$ & \\
2 & 12 & 6 & $0.37(0.23-0.61)$ & \\
$3+$ & 7 & 3 & $0.28(0.14-0.56)$ & $<0.001$ \\
\hline
\end{tabular}

\subsection{Predictors of Common Mental Disorder}

Table 2 shows the overall prevalence rates of any CMD by district and by gender. The overall prevalence of CMD was 31 per 1,000, and the prevalence was higher in women than in men in each district.

Table 2. Prevalence rates of any CMD by districts and gender.

\begin{tabular}{llll}
\hline Prevalence (Per 1,000 in last 6 months) & Temeke & Ilala & Combined \\
\hline Men & 38 & 14 & 25 \\
Women & 43 & 29 & 36 \\
All Adults & 41 & 23 & 31 \\
\hline
\end{tabular}

Data from the two areas were combined to investigate correlates of any CMD (see Table 3).

The prevalence was higher among females, people aged 16-24 and lowest among the married or cohabitating although these associations were not significant. Household status was significantly associated with CMD ( $\mathrm{p}<0.001)$ although given the very low prevalence among household heads (cell < 5), this finding should be considered with caution. The prevalence of any CMD was significantly higher among the unemployed compared to those with employment $(p=0.01)$ but there were no other significant associations with socio-economic factors. There was a strong and significant relationship between any CMD and number of recent life events ( $<<0.001)$, with CMD was highest among those who reported three or more stressful experiences in the preceding six months.

There was no clear relationship between social support and CMD although rates were highest among those that perceived no lack of social support and people with large social support networks.

Factors significantly associated with any CMD (employment status and recent life events but not household status due to small cell size) as well as factors that varied significantly by area (ethnicity and housing tenure) were included in the multivariate logistic regression modelling. Gender and age 
included for a priori reasons. Number of recent life events was the only factor independently associated with CMD (Table 3).

Table 3. Unadjusted and adjusted odds ratios for demographic and socio-economic variables and common mental disorder.

\begin{tabular}{|c|c|c|c|c|}
\hline & $\begin{array}{c}\text { Sample } \\
\text { size }\end{array}$ & $\begin{array}{c}\text { Prevalence } \\
\text { of CMD (\%) }\end{array}$ & $\begin{array}{c}\text { Unadjusted odds ratio } \\
(95 \% \mathrm{CI}) \\
\end{array}$ & $\begin{array}{c}\text { Adjusted odds ratio } \\
(95 \% \mathrm{CI}) \\
\end{array}$ \\
\hline \multicolumn{5}{|l|}{ Gender } \\
\hline Male & 393 & 2.5 & 1.00 & \\
\hline Female & 506 & 3.6 & $1.41(0.65-3.10)$ & \\
\hline \multicolumn{5}{|l|}{ Age } \\
\hline $16-24$ & 275 & 4.7 & 1.00 & \\
\hline $25-34$ & 308 & 3.2 & $0.68(0.29-1.57)$ & \\
\hline $35+$ & 316 & 1.6 & $0.32(0.11-0.92)$ & \\
\hline \multicolumn{5}{|l|}{ Marital Status } \\
\hline Married/cohabitating & 495 & 2.4 & 1.00 & \\
\hline Single & 327 & 4.0 & $1.67(0.75-3.70)$ & \\
\hline Widowed/divorced/ separated & 75 & 4.0 & $1.68(0.46-6.09)$ & \\
\hline \multicolumn{5}{|l|}{ Relationship to household } \\
\hline \multicolumn{5}{|l|}{ head } \\
\hline Head & 359 & 0.6 & 1.00 & \\
\hline Spouse/partner & 290 & 4.5 & $8.38(1.88-37.43)^{*}$ & \\
\hline Other & 250 & 5.2 & $9.79(2.19-43.78)^{*}$ & \\
\hline \multicolumn{5}{|l|}{ Ethnic group } \\
\hline Black African & 834 & 3.1 & 1.00 & \\
\hline Other & 63 & 3.2 & $1.02(0.24-4.39)$ & \\
\hline \multicolumn{5}{|l|}{ Employment status } \\
\hline Working & 300 & 1.7 & 1.00 & \\
\hline Unemployed & 49 & 10.2 & $6.71(1.87-24.10)^{*}$ & \\
\hline Economically inactive & 496 & 3.6 & $2.22(0.82-6.05)$ & \\
\hline \multicolumn{5}{|l|}{ Own/rent accommodation } \\
\hline Owns & 403 & 4.0 & 1.00 & \\
\hline Rents & 463 & 2.6 & $0.64(0.30-1.38)$ & \\
\hline Rent free & 29 & 0.0 & - & \\
\hline \multicolumn{5}{|l|}{ Type of accommodation } \\
\hline Whole house & 386 & 3.4 & 1.00 & \\
\hline Rooms/flat/other & 510 & 2.9 & $0.87(0.41-1.85)$ & \\
\hline \multicolumn{5}{|l|}{ Age left full time education } \\
\hline 13 or under/Never went & 52 & 1.9 & 1.00 & \\
\hline $14-16$ & 337 & 3.0 & $1.56(0.20-12.44)$ & \\
\hline $17+$ years & 420 & 2.9 & $1.5(0.91-11.78)$ & \\
\hline \multicolumn{5}{|l|}{ Income } \\
\hline Yes & 354 & 4.5 & 1.00 & \\
\hline No & 476 & 2.3 & $0.50(0.23-1.09)$ & \\
\hline
\end{tabular}


Table 3. Cont.

\begin{tabular}{|c|c|c|c|c|}
\hline \multicolumn{5}{|c|}{ Perceived social support } \\
\hline Severe lack & 173 & 2.1 & 1.00 & \\
\hline Moderate lack & 288 & 3.1 & $1.36(0.41-4.49)$ & \\
\hline No lack & 341 & 4.1 & $1.81(0.59-5.58)$ & \\
\hline \multicolumn{5}{|c|}{$\begin{array}{l}\text { Size of Primary Social } \\
\text { support group }\end{array}$} \\
\hline $0-3$ & 130 & 1.5 & 1.00 & \\
\hline $4-8$ & 411 & 2.9 & $1.92(0.43-8.71)$ & \\
\hline 9 or more & 358 & 3.9 & $2.6(0.58-11.62)$ & \\
\hline \multicolumn{5}{|c|}{ Number of life events } \\
\hline None & 576 & 0.7 & 1.00 & 1.00 \\
\hline 1 & 206 & 4.9 & $7.30(2.26-23.53)^{*}$ & $7.22(2.24-23.28)^{*}$ \\
\hline 2 & 46 & 6.6 & 10.07 (2.64-38.37)* & $9.91(2.60-37.80)^{*}$ \\
\hline $3+$ & 41 & 22.0 & $40.22(11.75-137.66)^{* *}$ & $39.83(11.06-136.78)^{* *}$ \\
\hline
\end{tabular}

Life events were also entered into the multivariate model by type of event rather than number of events again adjusting for factor associated with any CMD (employment status and recent life events), factors that varied significantly by area (ethnicity and housing tenure) and age and gender for a priroi reasons. Having experienced relationship difficulties, income instability and death of a loved one in the last six months remained independently associated with CMD (Table 4).

Table 4. Odds ratios for different categories of life events and mental disorder.

\begin{tabular}{|c|c|c|c|c|}
\hline & Sample size & $\begin{array}{c}\text { Prevalence of } \\
\text { CMD (\%) }\end{array}$ & $\begin{array}{c}\text { Unadjusted odds } \\
\text { ratio }(95 \% \mathrm{CI}) \\
\end{array}$ & $\begin{array}{c}\text { Adjusted odds ratio } \\
(95 \% \mathrm{CI})\end{array}$ \\
\hline \multicolumn{5}{|c|}{ Health risks } \\
\hline No & 815 & 2.7 & 1.00 & \\
\hline Yes & 84 & 7.1 & $2.77(1.09-7.04)^{*}$ & \\
\hline \multicolumn{5}{|c|}{ Relationship problems } \\
\hline No & 851 & 2.1 & 1.00 & 1.00 \\
\hline Yes & 48 & 20.8 & $12.18(5.27-28.17)^{* * *}$ & $8.39(3.39-20.76)^{* * *}$ \\
\hline \multicolumn{5}{|c|}{ Income instability } \\
\hline No & 805 & 1.7 & 1.00 & 1.00 \\
\hline Yes & 94 & 14.9 & $9.89(4.55-21.48)^{* * *}$ & $6.63(2.91-15.12)^{* * *}$ \\
\hline \multicolumn{5}{|c|}{ Death of a loved one } \\
\hline No & 702 & 2.1 & 1.00 & 1.00 \\
\hline Yes & 197 & 6.6 & $3.24(1.51-6.92)^{* *}$ & $2.31(1.01-5.25)^{*}$ \\
\hline \multicolumn{5}{|c|}{ Legal issues } \\
\hline No & 859 & 2.7 & 1.00 & \\
\hline Yes & 40 & 12.5 & $5.19(1.86-14.47)^{* *}$ & \\
\hline
\end{tabular}

${ }^{a}$ Adjusted for age, sex, employment status, ethnicity, housing tenure and other event types;

${ }^{*} \mathrm{p}<0.05 ;{ }^{*} \mathrm{p}<0.01 ;{ }^{* * *} \mathrm{p}<0.001$. 


\section{Discussion}

\subsection{Main Findings}

To the best of our knowledge, this is the first community-based epidemiological study of common mental disorders in Tanzania, and also the first in Africa to extend the study of risk factors for CMD to household status, ethnicity, housing tenure, accommodation type, social support and area economic indicators. The main findings were that the 6 month prevalence of CMD was 41 per 1,000 and 23 per 1,000 in the respective study communities; and that across areas, CMD was independently associated with recently experiencing one or more stressful life events. There was no significant gender difference in prevalence of CMD.

\subsection{Comparison with Other African Prevalence Studies}

The prevalence rates found are relatively low compared to most other recent studies in sub Saharan Africa-see Table 5. An earlier review suggested the prevalence rate of CMD in Africa range between 8 and 43\%, depending on the instrument used and population sampled [32]. Wide variation is also found in other regions of the world. The lifetime rate of any disorder across 17 countries was found to range between 12 and $47 \%$ [33].

However, past-year rates in Nigeria are comparable to our findings, where the prevalence of any anxiety and any mood disorder was $4.1 \%$ and $1.3 \%$ respectively [34]. Also consistent with the current findings, [35] in Nigeria reported an overall rate of depression of $5.2 \%$ across an urban and rural community.

Table 5. Prevalence studies of common mental disorders in sub Saharan Africa.

\begin{tabular}{|c|c|c|c|c|c|}
\hline Country & Author & Setting & Number & Measure & Prevalence \\
\hline Lesotho & $\begin{array}{l}\text { Hollifield et al. } \\
1990\end{array}$ & Rural & 356 & DIS & $\begin{array}{l}23.5 \% \mathrm{~F} \\
14.7 \% \mathrm{M}\end{array}$ \\
\hline Zimbabawe & $\begin{array}{l}\text { Abas \& Broadhead, } \\
1997\end{array}$ & Urban & 172 & SSQ & $\begin{array}{l}15.7 \% \text { F } 1 \text { month, } 30.8 \% \text { F } \\
1 \text { year }\end{array}$ \\
\hline South Africa & $\begin{array}{l}\text { Haavenaar et al. } \\
2008\end{array}$ & Periurban & 209 & SRQ & $34.9 \% \mathrm{M}$ and $\mathrm{F}$ \\
\hline South Africa & $\begin{array}{l}\text { Haavenaar et al. } \\
2008\end{array}$ & Rural & 222 & SRQ & $27.0 \% \mathrm{M}$ and $\mathrm{F}$ \\
\hline South Africa & Hamad et al. 2008 & Urban & 257 & CES-D & $\begin{array}{l}64.5 \% \mathrm{~F} \\
50.4 \% \mathrm{M}\end{array}$ \\
\hline Nigeria & Gureje et al. 2006 & $\begin{array}{l}\text { Probability sample } \\
\text { of } 8 \text { states }\end{array}$ & 4,984 & CIDI & $\begin{array}{l}12.1 \% \text { life time; } 5.8 \% 12 \\
\text { month prevalence } \\
\mathrm{M} \text { and } \mathrm{F}\end{array}$ \\
\hline Ethiopia & Tafari et al. 1991 & Rural & 2,000 & SRQ & $11.2 \% \mathrm{M}$ and $\mathrm{F}$ \\
\hline Uganda & $\begin{array}{l}\text { Orley and Wing } \\
1979\end{array}$ & Rural & & PSE & \\
\hline Sudan & $\begin{array}{l}\text { Rahim and } \\
\text { Cederblad }\end{array}$ & Urban & & SRQ/DSM III & $16.6 \% \mathrm{M}$ and $\mathrm{F}$ \\
\hline
\end{tabular}




\subsection{Social Determinants of CMD}

In the current study, the prevalence of CMD was higher among women although not significantly. Gureje and colleagues [34], in Nigeria also failed to demonstrate a difference between genders, and although consistent with Britain [36], and other parts of the world such as Brazil [37]. Higher rates among women have commonly been found in Africa including Zimbabwe [38], Ethiopia [39], and South Africa [40].

Older age (30+ years) was associated with lower odds of CMD, compared to people aged 16-24, whereas in Ethiopia rates were highest in people aged 35-44 [39], and 50-64 in Nigeria [34]. Patel and colleagues [41], in five low- and middle-income countries and Lima and colleagues [37], in Brazil also found higher rates in older age groups. In Britain, the peak age groups were 50-54 for men and 45-49 for women [19].

Marital status was not significantly associated with disorder although single, separated, divorced or widowed people had the highest rates of CMD. The lack of significant association is consistent with recent reports from Nigeria [34], and South Africa [40], although previous studies have identified marital status as a risk for CMD in developing countries (e.g., [21,42-45]), with higher rates in the widowed, separated and divorced reported in Pakistan [46], Ethiopia [39], and Brazil [37].

In our study of urban Tanzania, people who were not head of household had higher rates of CMD and few household heads reported symptoms. Similarly, a study in South Africa [47], found higher rates of illness in people with lower subjective social status and independent decision making.

Higher rates of disorder were found in non-Africans. In Britain rates were higher in South Asian and "other" groups than in white or black groups [36]. These findings support the view that ethnic minorities in a country have rates of illness which are both higher than indigenous populations, and higher than the populations of their former country [48]. On the other hand in South Africa, studies show higher rates in African rather than white populations, which probably reflects the socio-economic disparities of the two groups (e.g., Hamad et al. 2008 [47]).

There are previous African-based mental health surveys which have reported associations with socio-economic factors. A 2003 review identified 11 studies from developing countries that reported associations between CMD and indicators of poverty although only two were sub-Saharan African [49]. In the current study, rates of disorder were highest in people who left full time education between the ages of 14 and 16 compared to those who left at 13. In contrast, in surveys in Zimbabwe [41], Pakistan [46], Brazil [37], and Burundi [50], it was found that low education levels were strongly associated with CMD, and indeed British rates of CMD were higher in those who leave school before 16 compared to those who completed school [28].

In Tanzania, as in Britain [36], the unemployed had significantly higher rates of disorder although the association did not remain after adjustment for other factors. Similarly in Zimbabwe, Patel [41], found the association with unemployment was not consistent after adjustment for age and sex.

Income was not significantly associated with CMD although higher rates of disorder were among those with an income. This surprising finding however is consistent with Gureje and colleagues [34], who found having an income to significantly increase the risk of any disorder, suggesting that receipt of a monetary income may bring with it additional life stress, possibly caused by the social demands and responsibilities experienced by those with an income. 
Two urban areas of differing socio-economic circumstances were surveyed in this study, Median estimated household monthly income in 2002 was 17,752 TZS (\$US 20.90) in Mtoni-Saba Saba, significantly lower than in Ilala 22,308 TZS (\$US 26.26) [51]. Living in the less affluent area of Mtoni Saba Saba was associated with higher rates of disorder (4.1\%) compared to the middle-income area of Ilala Ilala (2.3\%) although the difference was not statistically significant.

\subsection{Life Events and CMD}

There was a strong positive association between life events and CMD in urban Tanzania, where the odds of experiencing CMD were far greater for those who had experienced three or more in the preceding six months. Tafari and colleagues [39], in Ethiopia found that people who had experienced six or more stressful life events in the past year had 2.7 times greater odds of neurosis. A strong association between life events and depression has been reported in Zimbabwe [52], and Pakistan [46]. The relationship between life events and CMDs has been demonstrated elsewhere including Brazil [37], and is well established in Britain [53]. It has been suggested that in addition to key demographic characteristics, life events have greater influence on mental health than poverty per se in the developing context [54].

\subsection{Social Support and CMD}

Those with no social support were significantly more likely to have CMD in the UK [28], while the direction of the association was opposite in Tanzania, with the rate of CMD increasing with increasing amount of perceived support and size of support group. A study in South Africa [55], found no independent association between levels of social support and psychological distress, while a Zimbabwean study found crisis support from family members to be protective [56]. However, a UK mental health survey of different ethnic groups found that high CIS-R scores (indicating presence of CMD) was associated with higher number of friends and relatives among Bangladeshi and Indian respondents, but not the other ethnic groups in the survey [57]. Further investigation is warranted in Tanzania. It may be that those with a large social network found that the support which may be derived from the group was outweighed by the heavy familial demands made by large extended families for financial and practical support.

Few African-based mental health surveys have reported associations with socio-economic factors. A 2003 review identified 11 studies from developing countries that reported associations between CMD and indicators of poverty although only two were sub-Saharan African [49]. In the current study, rates of disorder were highest in people who left full time education between the ages of 14 and 16 compared to those who left at 13. In contrast, surveys in Zimbabwe [43], Pakistan [34], Brazil [35], and Burundi [50], it was found that low education levels were strongly associated with CMD. British rates were higher in those who leave school before 16 compared to those who completed school [27]. 


\subsection{Limitations of the Study}

The sampling frame was well-defined and based on bi-annual demographic surveillance for the AMMP. However, current findings are specific to the two wards in urban Dar es Salaam and are not necessarily applicable to other parts of Tanzania, particularly rural areas. The combination of pencil and paper administration of the survey and the complex routing of the CIS-R resulted in missing data and possible underestimation of prevalence rates. In the regression analysis, data from the two areas were combined without weighting for the different probabilities of selection although variables that differed significantly between areas were included in the logistic regression modelling.

\section{Conclusions}

This study of two urban areas of Tanzania of differing levels of poverty did not find a significant difference in rates of CMD between areas although the poorest area did have higher rates of disorder. CMD is highly associated with exposure to traumatic life events in urban Dar es Salaam, particularly events involving relationship difficulties and financial instability. The effect of social support was counter intuitive and deserves further research. Efforts to address poverty and disadvantage in low income countries such as Tanzania will need to take mental health into account and address the difficult circumstances and environments within which people live and work.

\section{Acknowledgments}

The study was funded by the UK Department for International Development (DFID). We are grateful to the Dar es Salaam Surveillance site team with a special thanks to Esther Mandara and the Dar es Salaam interviewers. AMMP was a project of the Tanzanian Ministry of Health funded by the UK DFID and implemented in partnership with of Newcastle University, UK. The funders of the study had no role in study design, data collection, data analysis, data interpretation, or writing of the manuscript. All authors had full access to all the data in the study, and the corresponding author had final responsibility for the decision to submit for publication.

\section{References}

1. United Nations. The Millennium Development Goals Report; United Nations: New York, NY, USA, 2007.

2. The World Bank. African Development Indicators 2005; The World Bank: Washington, DC, USA, 2005.

3. Government of Tanzania. Development Vision 2025; Government Printer: Dar es salaam, Tanzania, 1997.

4. Government of Tanzania. National Strategy for Growth and Reduction of Poverty (2005-2010); Government Printer: Dar es salaam, Tanzania, 2005.

5. Government of Tanzania. Tackling Vulnerability: An Approach to Poverty Reduction; Government Printer: Dar es salaam, Tanzania, 2004. 
6. The Global Burden of Disease: 2004 Update; World Health Organisation: Geneva, Switzerland, 2008.

7. Mbatia, J.; Jenkins, R.; Singleton, N.; White, B. Prevalence of Alcohol, Nicotine and other substance use and hazardous alcohol use in Urban Tanzania, and Their Associated Risk Factors. Int. J. Environ. Res. Public Health 2009, 6, 1991-2006.

8. Kitange, H.M.; Machibya, H.; Black, J.; Mtasiwa, D.M.; Masuki, G.; Whiting, D.; Unwin, N.; Moshiro, C.; Klima, P.M.; Lewanga, M.; Alberti, K.; McLarty, D.G. Outlook for survivors of childhood in sub-Saharan Africa: adult mortality in Tanzania. BMJ 1996, 312, 216-220.

9. Unwin, N.; Mugusi, F.; Aspray, T.; Whiting, D.; Edwards, R.; Mbanya, J.C.; Sobgnwi, E.; Rashid, S.; Alberti, K. Tackling the emerging pandemic of non-communicable diseases in subSaharan Africa: The essential NCD health intervention project. Public Health 1999, 113, 141-146.

10. Ministry of Health and AMMP Team. Policy Implications of Adult Morbidity and Mortality, End of Phase 1 Report Summary; Technical Report No. 1; Tanzania Ministry of Health: Dar es Salaam, Tanzania, 1997.

11. Ministry of Health. Adult Morbidity and Mortality Project (AMMP) The Policy Implications of Tanzania's Mortality Burden, Volume 1 A Ten-Year Community-Based Perspective; Tanzania Ministry of Health: Dar es Salaam, Tanzania, 2002.

12. Lewis, G.; Pelosi, A.; Araya, R.C.; Dunn, G. Measuring psychiatric disorder in the community: a standardised assessment for use by lay interviewers. Psychol. Med. 1992, 22, 465-489.

13. Bebbington, P.E.; Nayani, T. The psychosis screening questionnaire. Int. J. Methods Psychiatr. Res. 1995, 5, 11-20.

14. Saunders, J.B.; Aasland, O.G.; Babor, T.F.; de la Fuente, J.R.; Grant, M. Development of the alcohol use disorders identification test (AUDIT): WHO collaborative project on early detection of persons with harmful alcohol consumption II. Addiction 1993, 88, 791-804.

15. Jenkins, R.; Mbatia, J.; Singleton, N.; White, B.; Whiting, D. Psychotic symptoms and risk factors in Tanzanian urban surveillance sites of varying levels of poverty. Int. J. Environ. Res. Public Health 2010 (in press).

16. Lewis, G. Computerized assessments of psychiatric disorder using PROQSY. J. R. Soc. Med. 1992, 85, 403-406.

17. Jenkins, R.; Bebbington, P.; Brugha, T.; Farrell, M.; Gill, B.; Lewis, G.; Meltzer, H.; Petticrew, M. The National Psychiatric Morbidity Surveys of Great Britain—Strategy and methods. Psychol. Med. 1997, 27, 765-774.

18. Meltzer, H.; Gill, B.; Petticrew, M.; Hinds, K. OPCS Survey of Psychiatric Morbidity: Report 1. The Prevalence of Psychiatric Morbidity among Adults Ages 16-64 Living in Private Households in Great Britain; HMSO: London, UK, 1995.

19. Singleton, N.; Bumpstead, R.; O’Brien, M.; Lee, A.; Meltzer, H. Psychiatric Morbidity among adults living in private households, 2000. Int. Rev. Psychiatry 2003, 15, 65-73.

20. Patel, V.; Kirkwood, B.R.; Pednekar, S.; Weiss, H.; Mabey, D. Risk factors for common mental disorders in women: Population-based longitudinal study. Br. J. Psychiatry 2006, 189, 547-555.

21. Patel, V.; Mann, A. Etic and emic criteria for non-psychotic mental disorder: a study of the CISR and care provider assessment in Harare. Soc. Psychiatry Psychiatr. Epidemiol. 1997, 32, 84-89. 
22. Wickramasinghe, S.C.; Rajapakse, L.; Abeysinghe, R.; Prince, M. The Clinical Interview Schedule-Revised (CIS-R): modification and validation in Sri Lanka. Int. J. Methods Psychiatr. Res. 2002, 11, 169-177.

23. Ngoma, M.C.; Prince, M.; Mann, A. Common mental disorders among those attending primary health clinics and traditional healers in urban Tanzania. Br. J. Psychiatry 2003, 183, 349-355.

24. World Health Organization. International Statistical Classification of Diseases and Related Health Problems. Tenth Revision; World Health Organization: Geneva, Switzerland, 1993.

25. Jenkins, R.; Lewis, G.; Bebbington, P.; Brugha, T.; Farrell, M.; Gill, B.; Meltzer, H. The National Psychiatric Morbidity Surveys of Great Britain-Initial Findings from the Household Survey. Psychol. Med. 1997, 27, 775-790.

26. Singleton, N.; Meltzer, H.; Gatward, R.; Coid, J.; Deasy, D. Psychiatric Morbidity among Prisoners in England and Wales: A Survey Carried Out in 1997 by the Social Survey Division of ONS on Behalf of the Department of Health; The Stationery Office: London, UK, 1998.

27. Breeze, E.; Maidment, A.; Bennett, N.; Flatley, J.; Carey, S. Health Survey for England, 1992; HMSO: London, UK, 1994.

28. Singleton, N.; Bumpstead, R.; O’Brien, M.; Lee, A.; Meltzer, H. Psychiatric Morbidity among Adults Living in Private Households, 2000; TSO: London, UK, 2001.

29. Brugha, T.; Bebbington, P.E.; MacCarthy, B.; Potter, J.; Sturt, E.; Wykes, T. Social networks, social support and the type of depressive illness. Acta Psychiatr. Scand. 1987, 76, 664-673.

30. Brugha, T.; Wing, J.; Brewin, C.; MacCarthy, B.; Lesage, A. The relationship of social network deficits with deficits in social functioning in long-term psychiatric disorders. Soc. Psychiatry Psychiatr. Epidemiol. 1993, 28, 218-224.

31. Statistical Package for Social Sciences, Windows 15; SPSS Inc: Chicago, IL, USA, 2006.

32. Institute of Medicine. Neurological, Psychiatric, and Developmental Disorders: Meeting the Challenge in the Developing World; National Academy Press: Washington, DC, USA, 2001.

33. Kessler, R.; Angermeyer, M.; Anthony, J.; De Graaf, R.; Demyttenaere, K.; Gasquet, I.; De Girolamo, G.; Gluzman, S.; Gureje, O.; Haro, J.; Kawakami, N.; Karam, A.; Levinson, D.; Medina Mora, M.; Oakley Browne, M.; Posada-Villa, J.; Stein, D.; Tsang, c.; Aguilar-Gaxiola, S.; Alonso, J.; Lee, S.; Heeringa, S.; Pennell, B.; Berglund, P.; Gruber, M.; Petukhova, M.; Chatterji, S.; Üstün, T. Lifetime prevalence and age-of-onset distributions of mental disorders in the World Health Organization's World Mental Health Survey Initiative. World Psychiatry 2007, 6, 168-176.

34. Gureje, O.; Lasebikan, V.O.; Kola, L.; Makanjuola, V.A. Lifetime and 12-month prevalence of mental disorders in the Nigerian Survey of Mental Health and Well-Being. Br. J. Psychiatry 2006, 188, 465-471.

35. Amoran, O.; Lawoyin, T.; Lasebikan, V. Prevalence of depression among adults in Oyo State, Nigeria: A comparative study of rural and urban communities. Aust. J. Rural Health 2007, 15, 211-215.

36. Jenkins, R.; Bebbington, P.; Brugha, T.S.; Farrell, M.; Lewis, G.; Meltzer, H. British Psychiatric Morbidity Survey. Br. J. Psychiatry 1998, 173, 4-7. 
37. Lima, M.S.; Beria, J.U.; Tomasi, E.; Conceicao, A.T.; Mari, J.J. Stressful life events and minor psychiatric disorders: an estimate of the population attributable fraction in a brazilian community-based study. Int. J. Psychiatry Med. 1996, 26, 211-222.

38. Patel, V.; Todd, C.; Winston, M.; Gwanzura, F.; Simunyu, E.; Acuda, W.; Mann, A. Common mental disorders in primary care in Harare, Zimbabwe: associations and risk factors. $\mathrm{Br}$. $\mathrm{J}$. Psychiatry 1997, 171, 60-64.

39. Tafari, S.; Aboud, F.E.; Larson, C.P. Determinants of mental illness in a rural Ethiopian adult population. Soc. Sci. Med. 1991, 32, 197-201.

40. Havenaar, J.M.; Geerlings, M.I.; Vivian, L.; Collinson, M.; Robertson, B. Common mental health problems in historically disadvantaged urban and rural communities in South Africa: prevalence and risk factors. Soc. Psychiatry Psychiatr. Epidemiol. 2008, 43, 209-215.

41. Patel, V.; Araya, R.; de Lima, M.; Ludermir, A.; Todd, C. Women, poverty and common mental disorders in four restructuring societies. Soc. Sci. Med. 1999, 49, 1461-1471.

42. Bondestam, S.; Garssen, J.; Abdulwakil, A.I. Prevalence and treatment of mental disorders and epilepsy in Zanzibar. Acta Psychiatr. Scand. 1990, 81, 327-331.

43. Gureje, O.; Obikoya, B.; Ikuesan, B.A. Prevalence of specific psychiatric disorders in an urban primary care setting. East Afr. Med. J. 1992, 69, 282-287.

44. Dhadphale, M.; Ellison, R.H. The frequency of mental disorders in the outpatients of two Nyanza hospitals. Cent. Afr. J .Med. 1983, 29, 29-32.

45. Ndetei, D.M.; Muhangi, J. The prevalence and clinical presentation of psychiatric illness in a rural setting in Kenya. Br. J. Psychiatry 1979, 135, 269-272.

46. Husain, N.; Creed, F.; Tomenson, B. Depression and social stress in Pakistan. Psychol. Med. 2000, 30, 395-402.

47. Hamad, R.; Fernald, L.C.H.; Karlan, D.S.; Zinman, J. Social and economic correlates of depressive symptoms and perceived stress in South African adults. J. Epidemiol. Community Health 2008, 62, 538-544.

48. Brugha, T.; Jenkins, R.; Bebbington, P.; Meltzer, H.; Lewis, G.; Farrell, M. Risk factors and the prevalence of neurosis and psychosis in ethnic groups in Great Britain. Soc. Psychiatry Psychiatr. Epidemiol. 2004, 39, 939-946.

49. Patel, V.; Kleinman, A. Poverty and common mental disorders in developing countries. Bull. World Health Organ. 2003, 81, 609-615.

50. Baingana, F.; Dabalen, A.; Menye, E.; Prywes, M.; Rosholm, M. Mental Health and Socio-Economic Outcomes in Burundi, HNP Discussion paper; The World Bank: Washington, DC, USA, 2004.

51. Abeyasekera, S.; Ward, P. Models for Predicting Expenditure per Adult Equivalent (for AMMP surveillance sentinel sites); Tanzanian Ministry of Health: Dar es Salaam, Tanzania, 2002.

52. Broadhead, J.C.; Abas, M.A. Life events, difficulties and depression among women in an urban setting in Zimbabwe. Psychol. Med. 1998, 28, 29-38.

53. Bebbington, P.; Wilkins, S.; Jones, P.; Foerster, A.; Murray, R.; Toone, B.; Lewis, S. Life events and psychosis. Initial results from the Camberwell Collaborative Psychosis Study. Br. J. Psychiatry 1993, 162, 72-79. 
54. Das, J.; Do, Q.-T.; Friedman, J.; McKenzie, D.; Scott, K. Mental health and poverty in developing countries: Revisiting the relationship. Soc. Sci. Med. 2007, 65, 467-480.

55. Lund, C.; Breen, A.; Flisher, A.J.; Kakuma, R.; Corrigall, J.; Joska, J.A.; Swartz, L.; Patel, V. Poverty and common mental disorders in low and middle income countries: A systematic review. Soc. Sci. Med. 2010 (in press).

56. Broadhead, J.; Abas, M.; Sakutukwa, G.; Chigwanda, M.; Garaura, E. Social support and life events as risk factors for depression among women in an urban setting in Zimbabwe. Soc. Psychiatry Psychiatr. Epidemiol. 2001, 36, 115-122.

57. Sproston, K.; Nazroo, J. Ethnic Minority Psychiatric Illness Rates in the Community (EMPIRIC)—Quantitative Report; National Centre for Social Research, Department of Epidemiology and Public Health, the Royal Free and University College Medical School, London, UK, 2002.

(C) 2010 by the authors; licensee MDPI, Basel, Switzerland. This article is an Open Access article distributed under the terms and conditions of the Creative Commons Attribution license (http://creativecommons.org/licenses/by/3.0/). 